\title{
The Development and Implementation of Marketing Information System Within Innovation: The Increasing of Innovative Performance
}

\author{
Ondrej Zizlavsky \\ Brno University of Technology \\ Czech Republic
}

\section{Introduction}

In his work, a prominent Czech expert on innovations, (Valenta, 2001), reached the conclusion that current tougher and tougher competition, globalization of production and markets, as well as implementation of new technologies mean that the success of businesses is dependent on effectiveness and intensity of innovation activities. Innovation is a process that is created via interactions between various actors, e.g. (Dolourex, 2004) and represents an important element of a company's future success. Each innovation is unique and specific for every entrepreneurship. American authors warn that innovation is more than just an idea or thought. It is bringing an idea to life (Tidd \& Bessant, 2009). Currently, innovation is considered a decisive condition of a competitive advantage in entrepreneurship. This is stressed by prominent Czech, as well as foreign experts; e.g. (Hamel \& Green, 2007; Kislingerova, 2008; Kosturiak \& Chal, 2008; Skarzynski \& Gibson, 2008). The course of the fading economic crisis that negatively impacted operation of current business unambiguously supports the inevitability of innovations. A company that strives to maintain and strengthen its position on the market has to implement a suitable innovation policy that would enable it to achieve a more advantageous position, in comparison with the competition. (Dinis, 2004) declares that the success of any innovation (and consequently, the competitive advantage of companies) is dependent on the marketing method of management, through which companies strive to adjust or (even better) foresee market trends. (Synek, 2011) also supported the idea that marketing of innovations plays a considerable role in the success of innovations. In their work, they declare that a competitive advantage can have a differential character in the form of supply of more sophisticated or more varied products that better suit the needs and wishes of users, or it can rest in improvement and better productivity of used production processes or increased quality of products. At the same time, in his work, Professor Maciariello presents and relates to the economist Peter F. Drucker who is known because of his statement that the purpose of existence of a company rests in creation of customers, and its primary tasks are innovation and marketing (Maciariello, 2008). Only they produce results; the remainder produces only costs. 
However, without putting innovations on the market, the implementation process is not complete and, therefore, innovation cannot be considered realized. Therefore, activities related to preparation of the market and relevant marketing activities for promotion of a new product have to take place in parallel with solution of technical problems. Even though a prepared product is technically perfect, there is no guarantee that people will accept it and utilize it in the long term. Therefore, if innovation should be successful, it has to be not only feasible, but also its result, the new product, has to be marketable. It has to catch the interest of customers and invoke their willingness to buy this product. Therefore, an important aspect affecting the perception of its output, e.g. behaviour of customers on target markets, cannot be forgotten in innovation activities. At the same time, in their work, the German authors declare that in their opinion, a large part of variations of success or failure is caused by factors that can be ranked with marketing in the broader sense of the word (Trommsdorff \& Steinhoff, 2006). Among them, there are strategic, as well as operative decisions and information from market research, from which such decisions are derived. In every case, such factors are linked to behaviour of target customers and competition. It is precisely the target market that decides if an innovation is accepted and, therefore, an innovation process successfully completed, e.g. (Tidd \& Bessant, 2009).

Overall, marketing has the task of understanding and managing innovations within companies and markets where the primary objective of an innovation rests in development of new or modification of old products, in order to improve profitability. The inevitable component of profitability is income and its amount depending on whether a company is able to satisfy customers' needs better than its competitors, e.g. (Hauser et al., 2006). In today's knowledge-based society, correct information can help a company to act against its competition, especially if such company has built a strong marketing information system that is able to quickly convert knowledge into values for a customer, e.g. (Allak, 2010). For its importance in competition effort, information ranks among very important assets of every company. Marketing decisions also have to be supported by information that helps marketing managers to decide what to produce, when to produce it, and for how much, e.g. (Chatzipanagioton et al., 2008). Such necessary information is provided by the marketing information system.

The objective of the article rests in summary and presentation of results of two primary research studies whose tasks rested in acquiring knowledge on the current state of management of innovations in companies of the South Moravian Region of the Czech Republic and formulate proposals for entrepreneurs leading to improvement of information support of effective management of marketing of innovations.

\section{Definition}

First, the terms "innovation", "innovative performance" and "marketing informational system" will be defined, as well as their properties and dimensions.

\subsection{Innovation}

There are numerous definitions of the concept of "innovation" existing in economic and business literature. The significance of innovation was highlighted as early as the beginning of the twentieth century by Schumpeter. He proposed a list of five types of innovations (Schumpeter, 1912): 
- Introduction of new products.

- Introduction of new methods of production.

- Opening of new markets.

- Development of new sources of supply for raw materials or other inputs.

- Creation of new market structures in an industry.

Based on Schumpeter's theory Oslo Manual (OECD, 2005) defines innovation as the implementation of a new or significantly improved product (good or service), or process, a new marketing method, or a new organisational method in business practices, workplace organisation or external relations.

The minimum requirement for an innovation is that the product, process, marketing method or organisational method must be new (or significantly improved) to the company. This includes products, processes and methods that companies are the first to develop and those that have been adopted from other companies or organisations. A company can make many types of changes in its methods of work, its use of factors of production and the types of output that improve its productivity and/or commercial performance. The Oslo Manual defines four types of innovations that encompass a wide range of changes in firms' activities:

- Product innovations involve significant changes in the capabilities of goods or services. Both entirely new goods and services and significant improvements to existing products are included.

- Process innovations represent significant changes in production and delivery methods.

- Organisational innovations refer to the implementation of new organisational methods. These can be changes in business practices, in workplace organisation or in the firm's external relations.

- Marketing innovations involve the implementation of new marketing methods. These can include changes in product design and packaging, in product promotion and placement, and in methods for pricing goods and services (OECD, 2005).

\subsection{Innovative performance}

Performance is a level of reached results by individuals, groups, organizations and their processes (European Foundation for Quality Management).

The innovative performance can be understood as the ability to transform innovation inputs into outputs, thus the ability to transform innovation potential into market implementation. Result of innovative performance is the (innovation) market success (Zizlavsky, 2009).

The innovative performance overarches the measurement of all stages from $R \& D$ to patenting and new product introduction. In other words, this definition of innovative performance in the broad sense focuses on both the technical aspects of innovation and the introduction of new products into the market, but it excludes the possible economic success of innovations as such (see also Ahuja and Katila, 2001; Ernst, 2001; Stuart, 2000).

\subsection{Marketing information system}

Marketing information system is the structure of people, equipment and procedures used to gather, analyse and distribute information needed by an organization. These are the data to be used as a basis for decision-making (Reid \& Bojanic, 2009). 
Full definition of marketing information system and its concept can be found in Chapter 6 .

\section{Material and methods}

For the research process, the following hypotheses were defined:

H1: $\quad$ The majority of innovation activities are undertaken by large and medium-sized companies that have sufficient funds for it.

H2: $\quad$ Direct expression of effects of innovation activities strongly depends on market development prognoses, and marketing information systems have to help with their predictions.

With regards to the identified objective of research projects - learn and study the current state of issues of management of innovation activities and their information support as these areas are currently being solved in Czech, as well as foreign expert literature and practice in Czech companies - and the method of their fulfilment, when processing the research, the system approach and the following scientific work methods were utilized:

- Analysis is used as a method of acquiring new knowledge and its interpretation. When processing secondary data, a method of secondary analysis was utilized. A source of secondary data was professional literature, especially foreign - books, magazines, articles from scientific and professional databases (Emerald, Science Direct, etc.) or proceedings from scientific conferences, with respect to their professional level and relevance.

- Questionnaire (see below).

- Comparison was utilized for mutual comparison of results of the questionnaire inquiry of individual companies. This basic benchmarking approach selected more innovative companies for further personal interviews with the company's management.

- Inquiry with the objective to acquire the particular data and following discussion about acquired results and verification of their implementation and realization in practice was carried out in the form of personal interviews with companies' managements, i.e. especially with members of the top management, executive agents, or owners of production facilities.

- Content analysis was applied to study of texts processed and acquired in the course of interviews with managers of selected companies (interview transcriptions, personal supporting documents acquired from respondents).

- $\quad$ Synthesis is used especially when results are pronounced and during production of a methodical proposal for correct development of information support of innovation activities and, thereby, improved competitiveness of a company.

- Induction was utilized especially when generalizing all the findings achieved in the questionnaire inquiry. Verification of found dependencies was verified by application of deduction.

- Statistical methods were utilized when analysing primary data and their results are presented in tables in this report.

A questionnaire inquiry was carried out for the purpose of determination of the real state of solved issues of management and support of innovation activities. Before the research was commenced, the circle of respondents was duly considered. Research could have been limited based on a company's size, a field, and distribution of companies in the Czech 
Republic. After careful consideration, it was decided to carry out the research via a random selection between various-sized companies in the South Moravian Region of the Czech Republic (see Figure 1). The purpose of limitation to only the South Moravian Region rests in provision of larger predicative abilities of the questionnaire inquiry. Therefore, the executed research has much higher quality because we succeeded in (despite frequent unwillingness to fill out the questionnaire and provide cooperation) in collection of data from a relatively large number of companies within the whole region, which would not necessary happen within the whole Czech Republic, and individual data would be too scattered.

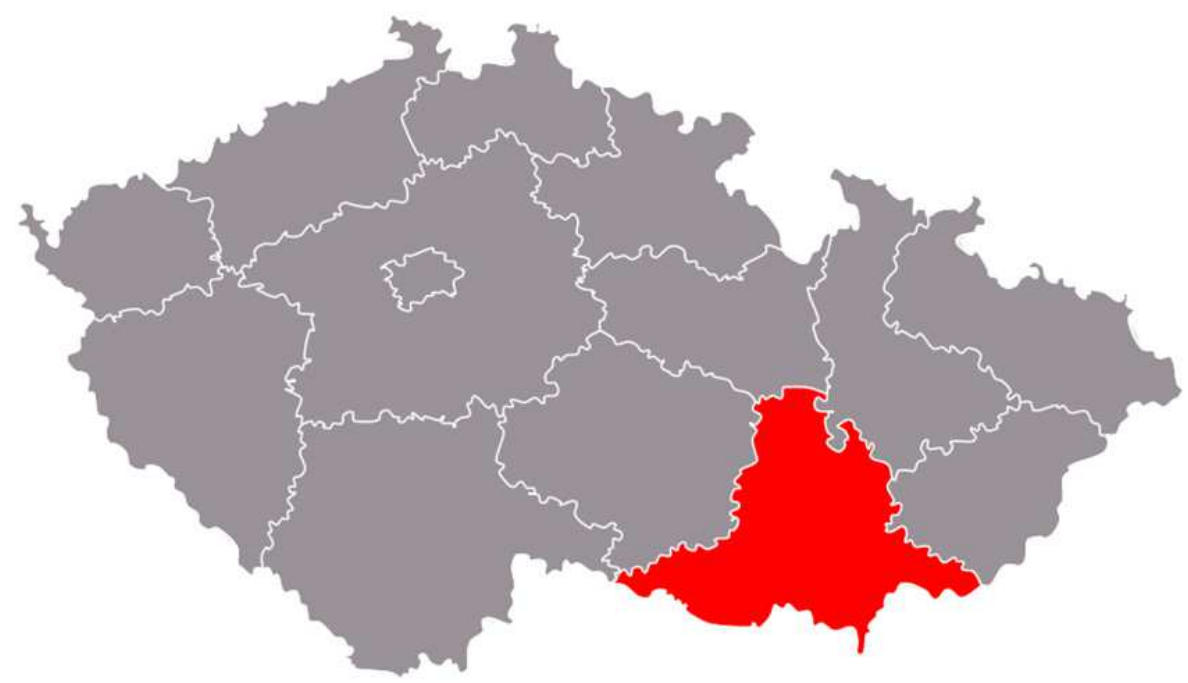

Fig. 1. South-Moravian Region of the Czech Republic

Within two consecutive research projects ${ }^{1}$ carried out in 2009 and 2010 under the sponsorship of the Internal Grant Agency of the Faculty of Business and Management Brno University of Technology, various approaches to management of the innovation process and creation of innovation strategy were examined in companies operating in the South Moravian Region of the Czech Republic. A total of 53, mostly production, companies participated in the first research project called Research of a level of development of innovation potential, creation, and evaluation of the innovation strategy of medium-sized and large machineindustry companies in the South Moravian Region in the Czech Republic. This project uncovered several unfavourable findings on the state of management of innovation activities. Therefore, this area was examined in detail in the second related research project called Development of knowledge for improvement of information support of the economic management of company development, in accordance with development of the business environment undertaken in

1 2009: Internal grant No. AD 179001M5 Research of the level of development of innovation potential, creation, and evaluation of the innovation strategy of medium and large-sized machine-industry companies in the South Moravian Region in the Czech Republic.

2010: Internal grant No. FP-S-10-17 Development of knowledge for improvement of information support of the economic management of company development, in accordance with development of the business environment. 
2010. This related and more extensive research took place from February to June 2010. The key was to approach as many respondents as possible and, therefore, to acquire a sufficiently large data scale factor for evaluation of the primary research. The inquiry itself provided quantitative, as well as qualitative data on the current state of the issue in question. Simplicity and relative briefness of the questionnaire, affecting a respondent's willingness to fill it out, was an important factor when creating the questionnaire. There were the following types of questions:

- With selectable answers and the option to select just one.

- With selectable answers and the option to select several answers at once.

- With pre-defined answers with an evaluation scale.

- Some questions had the option to fill in answers freely.

The questionnaire inquiry itself was carried out in two manners: By electronic questionnaire sent via e-mails. This form of inquiring is very advantageous from the aspect of filling in the questionnaire and, most of all, its evaluation. Absence of personal contact between the interviewer and the interviewee and, therefore, a possibility to provide supplemental data or explain a question, represents a slight disadvantage here. This insufficiency was eliminated by the subsequent phone or e-mail contact. Furthermore, by a personal contact with top management members, executive agents, or company owners in the South Moravian Region. This method of inquiring enables an interviewee to fully grasp the researched issue, and it also allows discussion of the topic in question, in which other valuable findings related to the researched issue are often involuntarily acquired. The disadvantage of this method rests in the big time demand of inquiring.

Two hundred and fifty questionnaires were mailed during the 2009 questionnaire survey. Companies contacted in the survey were selected from the Technological Profile of the Czech Republic (www.techprofil.cz), a database containing over 2,000 Czech companies engaged in business innovation. Author received a total of 53 correctly completed questionnaires, which represents a $21.2 \%$ return rate. That return rate can be considered as very good because return rates of mail-back questionnaires are usually less than $10 \%$. Even so it is necessary to determine the reasons why more than $71 \%$ of companies did not respond to the questionnaire. They can include negative experience with similar questionnaires, reluctance to participate because of a spate of similar questionnaires, and also because managers are much too busy. Detailed statistics of the 2009 questionnaire survey is in Table 1.

\begin{tabular}{|l|c|}
\hline $\begin{array}{l}\text { Number of addressed companies } \\
\text { a) By e-mail }\end{array}$ & 250 \\
b) By personal visit & 230 \\
\hline \hline Number of undelivered e-mails & 30 \\
\hline Number of partially filled questionnaires & 13 \\
\hline Number of completely filled questionnaires & 53 \\
\hline Real return & $21.2 \%$ \\
\hline
\end{tabular}

Table 1. Overall statistics of the questionnaire survey 2009

Within the questionnaire inquiry in 2010, a total of 800 respondents were addressed; of those, 750 in electronic form and 50 with printed questionnaires during a personal visit. 
Companies for the electronic research were selected from the database of contacts called the Technological Profile of CR (www.techprofil.cz) containing more than 2,000 Czech companies operating in the innovation business. The world-wide database, Kompass (cz.kompass.com), which contains more than 34,000 Czech companies, was further utilized. Search based on individual parameters as selected by a user is the guarantee of a required selection of innovating companies. Selection of companies for a personal visit was done based on contacts from the previous solution of the project. That represented a guarantee that companies that are actively involved in innovations and have something to say regarding this topic were included in the inquiry. A total of 139 correctly filled in questionnaires were returned, which represents a $17.4 \%$ rate of return. The aforementioned rate of return of the questionnaires can be considered very good because, for questionnaire inquiries, the expected rate of return is usually up to $10 \%$. Despite that, it is necessary to determine the causes of more than $82 \%$ of companies not reacting to the questionnaire. Among them could be bad experience with similar questionnaires or unwillingness to participate because of a clutter of similar questionnaires, as well as managers being very busy. The detailed statistics of the questionnaire inquiry is shown in Table 2.

\begin{tabular}{|l|c|}
\hline $\begin{array}{l}\text { Number of addressed companies } \\
\text { a) By e-mail }\end{array}$ & 800 \\
b) By personal visit & 750 \\
\hline \hline Number of undelivered e-mails & 50 \\
\hline Number of partially filled questionnaires & 35 \\
\hline Number of completely filled questionnaires & 139 \\
\hline Real return & $17.4 \%$ \\
\hline
\end{tabular}

Table 2. Overall statistics of the questionnaire survey 2010

Results of the questionnaire inquiry and interviews with top managers or executive agents enabled identification of significant insufficiencies when managing innovation processes in companies. They include, for example:

- In most cases, innovation is not a company's key process, and more often than not it is based on technology transfer rather than the company's internal research and development.

- Research and development activities start late, take too long and are expensive. This causes time loss and delays in marketing innovations. That in turn negatively impacts profits.

- Indifference and unwillingness of owners and top-level managers to take risks even in the case of promising innovations is manifest, and the prioritizing of certainty prevails.

- In companies, insufficient innovation culture predominates, which can of course be traced back to the lack of top management's interest.

- An unsuitable model of innovation process management is employed. There is no clearly defined problem description, innovation project management, coordination of activities, communication or cooperation. Vague objectives cause changes in the stages of the innovation process, missed deadlines and increased costs.

- $\quad$ There is no marketing information system in place for the modelling of future markets or the analysis of customers, their behaviour and unexpressed needs. Such insufficient knowledge of market requirements is a reason for excessively high innovation costs. 
Methods of solution of such insufficiencies were examined by researching professional literature of prominent Czech, as well as foreign authors and other sources, with the objective to contribute to a flawless, if possible, realization of innovation activities of a company. Such solution is already seen in the opening stage of the process where it is necessary to clearly define the customers' needs. Managers first have to utilize results of the market research for determination of its size, nature, customers' preferences, and supporting information for determination of prices of the target products and services. Once companies develop their internal processes towards satisfaction of particular customers' needs, availability of the correct information on the market size and customers' preferences represents the main road to success. In addition to determination of needs of existing and potential customers, this segment can be a source of information on completely new opportunities and markets for products and services, which the company can supply. Information on markets and customers serves the purpose of entry for the second step of the innovation process; i.e. the process of proposal and development of the current product or service. The aforementioned task represents a necessity of marketing development and implementation of the marketing information system.

\section{Research results}

Information acquired from the questionnaire inquiry in 2010 were evaluated in the following areas:

- Basic data on companies.

- $\quad$ Strategy and planning of the innovation process.

- Marketing.

- Cooperation.

- Evaluation of realized innovation activities and innovation barriers.

- Financing.

With regard to the scope of the chapter, thematic focus, and objective, only selected areas of the primary research will be presented here.

Questions from the first part of the questionnaire were related to the basic characteristic data of the company, such as the company's size, origin, market of operation, etc. Of the total of 139 respondents, the most participating companies in innovations in the South Moravian Region are micro companies (1-9 employees, with a turnover of up to 2 mil. EUR) $-43 \%$ of respondents, small companies (10-49 employees, with a turnover from 2 mil. EUR to 10 mil. EUR) $-32 \%$ of respondents, medium-sized companies (50-249 employees, with a turnover from 10 mil. EUR to 50 mil. EUR) - 13\% of respondents and the least participating in innovations are large companies (more than 250 employees, with a turnover exceeding 50 mil. EUR) $-12 \%$ of respondents. This result is probably caused by the fact that the larger the company is, the more demanding organization of any innovation changes in it is and, therefore, smaller companies with more flexible organization structures innovate more. Such finding refuted the original hypothesis that said that the majority of innovation activities are undertaken by large and medium-sized companies that have sufficient resources for it. The results of the answer about the size of the company are shown in more detail on Figure. 2. 


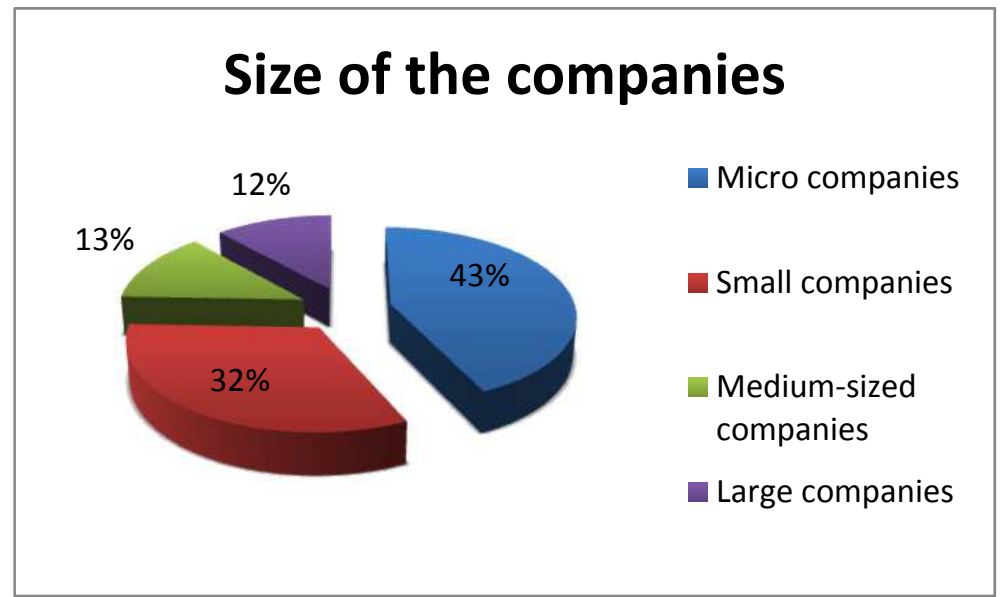

Fig. 2. Distribution of companies by size

The vast majority of addressed companies (83\% of respondents) have Czech owners, $10 \%$ of companies have foreign participation, and only $7 \%$ have foreign owners. Here, $65 \%$ of inquired companies are doing business within the Czech Republic; of it, 38\% operate on the domestic market within the whole CR, $27 \%$ of those questioned operate on regional markets only within the $\mathrm{CR}$ regions, $23 \%$ are doing business in the EU member and candidate countries, and the remaining $12 \%$ are doing business around the world. These facts are graphically shown on Figure 3 and Figure 4.

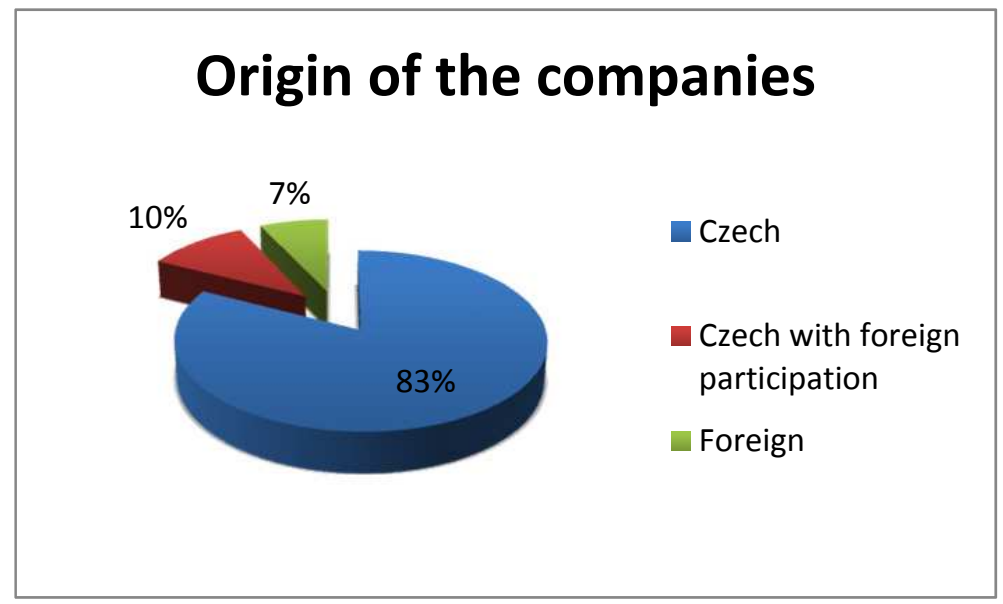

Fig. 3. Origin of the companies 


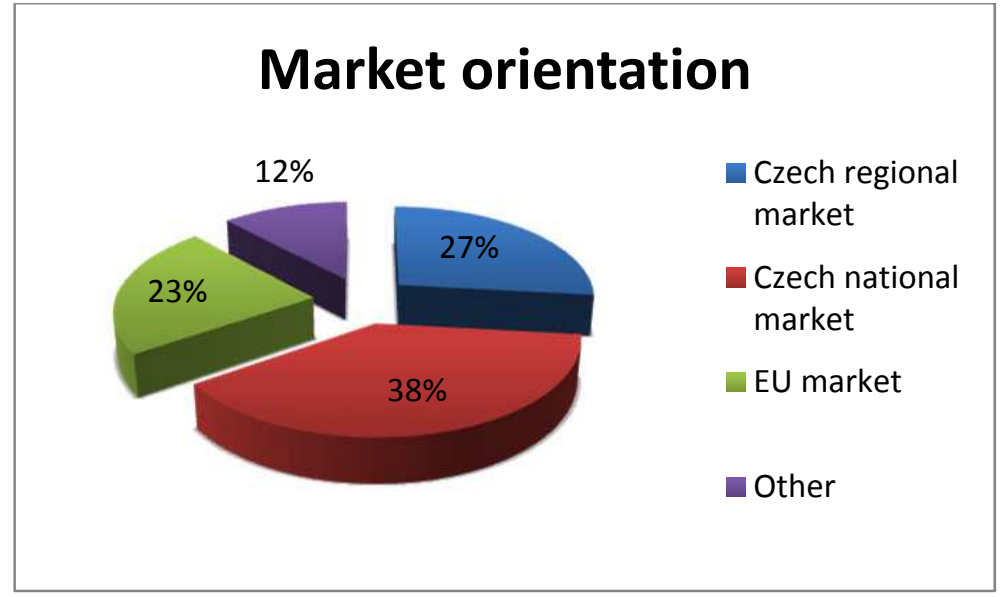

Fig. 4. Market orientation

\subsection{Strategy and planning area}

The strategy and planning area, in which respondents answered the question about what innovations were implemented by the company during the last three years and what importance they carry for the company, represented another part of the research. They could select from five predefined answers. Since respondents were able to select more answers for this question, a recalculation had to be carried out where a relative frequency was determined as a percentage of a number of selected answers to the total amount of respondents in the group. The following finding was derived from it:

- Product innovation: $28 \%$ occurrence of this answer.

- Process innovation: $25 \%$ occurrence of this answer.

- Organization innovation: $22 \%$ occurrence of this answer.

- Marketing innovation: $23 \%$ occurrence of this answer.

- None innovation: $2 \%$ occurrence of this answer.

These balanced results highlight the fact that product innovations often require process innovations, e.g. in the form of acquiring new production technology, and in order for these product innovations to be successful on the market and bring the company a higher value, it is often necessary to seek new distribution channels via marketing innovations.

Respondents also evaluated the importance of such innovations for the company based on the following scale: 1 - very important, 2 - important, 3 - neutral, 4 - not important, 5 completely unimportant. In the summary of the percentage ration of positive answers, i.e. values 1 (very important) and 2 (important), the order of individual possibilities was determined. Therefore, results show that respondents see the importance of innovations for their company in the following order: innovation of products, processes, organization, and marketing. Companies that have not implemented any innovations evaluate their importance as almost zero because the field or market in which the company participates or on which it operates, does not require an innovative approach and, therefore, they maintain 
the existing amount and quality of their output. Evaluation of the importance of individual types of innovations for companies in the South Moravian Region is shown in Table 3.

\begin{tabular}{|l||c|c|c|c|c|c|c|c|c|}
\hline & \multirow{2}{*}{ Average } & \multirow{2}{*}{$\begin{array}{c}\text { Standard } \\
\text { deviation }\end{array}$} & \multirow{2}{*}{ Modus } & \multicolumn{3}{|c|}{ Evaluating 1-5 (\%) } & \multirow{2}{*}{$\mathbf{1 + 2}$} \\
\cline { 5 - 9 } & & & $\mathbf{1}$ & $\mathbf{2}$ & $\mathbf{3}$ & $\mathbf{4}$ & $\mathbf{5}$ & $\mathbf{( \% )}$ \\
\hline \hline Product innovation & 2.2857 & 1.0302 & 2 & 18 & 29 & 14 & 12 & 27 & 47 \\
\hline Process innovation & 2.2419 & 0.9619 & 2 & 18 & 28 & 16 & 10 & 28 & 46 \\
\hline $\begin{array}{l}\text { Organizational } \\
\text { innovation }\end{array}$ & 2.3485 & 0.9127 & 2 & 15 & 28 & 26 & 8 & 23 & 43 \\
\hline Marketing innovation & 2.3226 & 0.9801 & 2 & 16 & 27 & 19 & 10 & 28 & 43 \\
\hline None innovation & 2.3125 & 0.8455 & 3 & 4 & 7 & 7 & 1 & 81 & 11 \\
\hline
\end{tabular}

Table 3. Importance of particular innovation types for companies

The main motives leading to commencement of such innovation activities are growth of revenues/profits, reaction to demand, increased quality, increased market share, and last but not least, inspiration by competitors. A review of the main motives for commencement of innovations and their importance is summarized in Table 4.



Table 4. Main motives for innovation activities and their importance

Results were derived from evaluation of respondents, again, based on the scale: 1 - very important, 2 - important, 3 - neutral, 4 - not important, 5 - completely unimportant. 
Inspiration by competitors represented an important motive as well. Therefore, it is possible to find so-called imitating companies among companies that implemented innovations, which created new innovations only for their own company, but not from the aspect of the market; i.e. they implemented new products or services already provided by competitors. A similar situation applies to process innovations where sources of innovations were modified or assumed technologies developed by competitors. As for inquired companies, innovators who assume and modify already known technologies unambiguously prevail.

Motives of innovation activities represent a starting point for innovation strategies. Strategic marketing and research, with a nomination by top management, participates in strategy proposal and formulation. The objective of every innovation strategy rests in achieving a competitive advantage leading to the company's improved position on the market (other objectives are derived). When creating a competitive advantage, first of all, companies have to be aware of their competitors' strategies, as well as their own competitive advantage.

Almost all inquired companies (93\% of respondents) are aware of their competitive advantage, which they have in comparison with their competitors. Only $7 \%$ are not aware of such advantage.

The process of formulating strategy results in production of an innovation plan that serves as the base for creation of other partial plans. When evaluating how much importance a company gives to production of innovation plans, the majority of companies replied that the biggest consideration goes to short-term plans, plans up to 1 year, and plans up to 2-3 years. Then, $8 \%$ of respondents do not compile any innovation plans and $1 \%$ of respondents compile plans that have different deadlines than defined (see Table 5).

\begin{tabular}{|c||c|c|c|c|c|c|c|c|c|}
\hline \multirow{2}{*}{} & \multirow{2}{*}{ Average } & \multirow{2}{*}{$\begin{array}{c}\text { Standard } \\
\text { deviation }\end{array}$} & \multirow{2}{*}{ Modus } & \multicolumn{5}{|c|}{ Evaluating 1-5 (\%) } & \multicolumn{1}{|c|}{$\mathbf{1 + 2}$} \\
\cline { 6 - 9 } & & & $\mathbf{1}$ & $\mathbf{2}$ & $\mathbf{3}$ & $\mathbf{4}$ & $\mathbf{5}$ & $\mathbf{( \% )}$ \\
\hline \hline Short-term plans & 2.1618 & 0.9642 & 2 & 23 & 28 & 20 & 8 & 21 & 51 \\
\hline 1 year plan & 2.4783 & 0.8095 & 2 & 8 & 34 & 30 & 8 & 20 & 42 \\
\hline 2-3 years plan & 2.5714 & 0.9974 & 3 & 12 & 17 & 23 & 13 & 35 & 29 \\
\hline None plan & 2.7500 & 0.8874 & 3 & 2 & 6 & 10 & 5 & 77 & 8 \\
\hline Other & 2.7500 & 0.4330 & 3 & 0 & 1 & 4 & 0 & 95 & 1 \\
\hline
\end{tabular}

Table 5. Innovation plans development

\subsection{Marketing area}

If we wish to seek sources of innovation ideas, it is necessary to verify if companies are able to identify, grab, and further process innovation impulses and ideas. Impulses for innovations in a company's vicinity come most often from external customers. That is closely followed by generation of impulses based on competitors. Utilization of impulses from professional literature, conferences, trade fairs, and exhibitions comes next. Innovation impulses inside a company come the most often from employees or as a result of a need to change technology and processes, via which products are produced or services offered. A list and evaluation of innovation impulses are shown in Table 6.

In-house collection of innovation ideas from employees is an interesting area. The brainstorming system is very often utilized during staff meetings on all the levels. Here, 
some companies also apply a motivation element in the form of a one-time bonus paid to an employee who solves a problem in question. On the other hand, other companies have a system based on collection points where employees may leave their impulses that are further evaluated during staff meetings. Based on realized interviews, it is possible to state that individual systems of communication with one's own employees when collecting innovative ideas differ from company to company. The bonus system represents a unifying element.

\begin{tabular}{|l||c|c|c|c|c|c|c|c|c|}
\hline & \multirow{2}{*}{ Average } & \multirow{2}{*}{$\begin{array}{c}\text { Standard } \\
\text { deviation }\end{array}$} & \multirow{2}{*}{ Modus } & \multicolumn{3}{|c|}{ Evaluating 1-5 (\%) } & \multirow{2}{*}{$\mathbf{1 + 2}$} \\
\cline { 5 - 8 } & & & $\mathbf{1}$ & $\mathbf{2}$ & $\mathbf{3}$ & $\mathbf{4}$ & $\mathbf{5}$ & $\mathbf{( \% )}$ \\
\hline \hline Customer & 1.3855 & 0.6555 & 1 & 66 & 26 & 2 & 2 & 2 & 92 \\
\hline Internet & 2.0988 & 0.8549 & 2 & 24 & 42 & 22 & 6 & 6 & 66 \\
\hline Competitors & 2.2561 & 0.8087 & 2 & 15 & 48 & 26 & 7 & 4 & 63 \\
\hline Employee & 2.1538 & 0.8332 & 2 & 21 & 39 & 26 & 5 & 9 & 60 \\
\hline Partners & 2.1842 & 0.8692 & 2 & 20 & 40 & 21 & 7 & 12 & 60 \\
\hline $\begin{array}{l}\text { Own research } \\
\text { into customers }\end{array}$ & 2.2836 & 0.9433 & 2 & 16 & 34 & 17 & 11 & 22 & 50 \\
\hline Suppliers & 2.4595 & 1.0804 & 2 & 19 & 30 & 17 & 21 & 13 & 49 \\
\hline Service & 2.4079 & 0.7809 & 3 & 12 & 34 & 38 & 5 & 11 & 46 \\
\hline Exhibitions & 2.4478 & 1.0116 & 3 & 17 & 21 & 27 & 13 & 22 & 38 \\
\hline Conferences & 2.7581 & 0.9278 & 2 & 4 & 28 & 20 & 20 & 28 & 32 \\
\hline $\begin{array}{l}\text { Professional } \\
\text { literature }\end{array}$ & 2.7727 & 0.8841 & 2 & 5 & 27 & 27 & 18 & 23 & 32 \\
\hline Public sector & 2.6379 & 1.0618 & 3 & 13 & 16 & 21 & 17 & 33 & 29 \\
\hline $\begin{array}{l}\text { Management } \\
\text { consultants }\end{array}$ & 2.9434 & 0.8559 & 3 & 4 & 14 & 27 & 17 & 38 & 18 \\
\hline
\end{tabular}

Table 6. Innovation incitation and its importance

When determining in which manner market information is shared in a company, it was discovered that $32 \%$ of companies are utilizing a high-quality information system (hereinafter the "IS") that is used by competent workers. That is a status in which a company has correctly implemented IS with correctly defined access possibilities for competent workers. That creates prerequisites for effective creation of strategic plans in a company and for sharing innovation impulses within individual company departments and between them. Unfortunately, only approx. 1/3 of inquired companies operate like this. For the other $32 \%$ of companies, there is practical knowledge that is sufficient and known to all the competent workers and, therefore, there is no need to engage in collecting and processing additional information. Such companies are utilizing know-how of their workers. When such worker leaves, a problem occurs. Non-sharing of information leads to growth of such worker's value and creation of pseudo-key positions in the company. For $29 \%$ of inquired companies, information on the market, contracts, and competitors is usually taken by competitive workers; however, they are not systematically shared for further utilization in the company. Such companies have IS, but only on the level of local stations, and mutual interconnection of information flow across a company is not utilized. Slow-down of flow of marketing information then expresses itself in delay in production of strategic plans or their frequent changes and corrections. The remaining 
$7 \%$ of inquired companies record information about the market by means of the company's information system, but workers do not optimally utilize it. Such companies do not pay enough attention to transfer of marketing information. Such companies are usually based on routine and practical experience and adjust their planning accordingly. Results of answers of inquiries companies to the transfer of market information issue are shown on Figure 5.

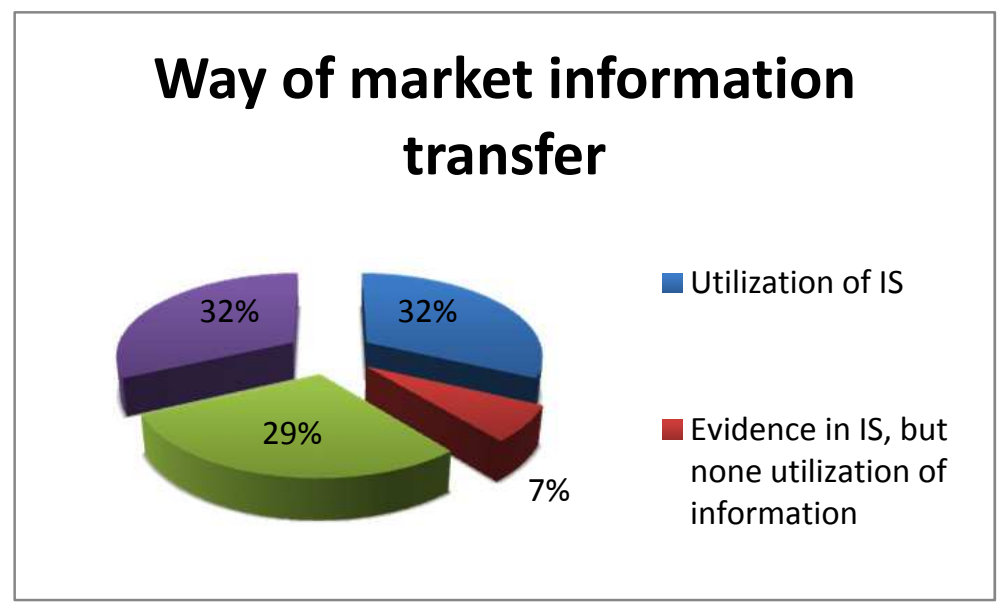

Fig. 5. Way of marketing information transfer

In addition to internal communication, external communication with the company's partners is important for a company as well, and in the majority of cases, it takes place via competent workers who register suggestions and comments ( $64 \%$ of respondents). Informal communication with partners via marketing staff is the basis. They are responsible for transfer of information to the company and for ensuring that it is undistorted. A quarter of companies communicate with partners via the company's information system $(25 \%$ of respondents). $6 \%$ of companies do not have the scope to react to partners' suggestions. Such companies behave as closed units and consider all the information related to their internal environment their know-how and, therefore, they usually are not too willing to communicate with their partners. The remaining $5 \%$ of companies communicate with partners only in the case of serious problems. Figure 6 presents results of communication with partners.

Next aim of a questionnaire research was to find out whether companies do evaluate the realized innovations activities and whether they utilize marketing information system for the evaluation of predictions of future markets. For that purpose the hypothesis H2 Direct expression of innovation activities effects significantly depends on market development forecasts. Marketing information systems have to support their predictions and following questions from the questionnaire will be used: Does your company evaluate the realized innovation projects? and Is there implemented and utilized marketing information system for future markets modelling in your company? 


\section{Way of communication with partners}

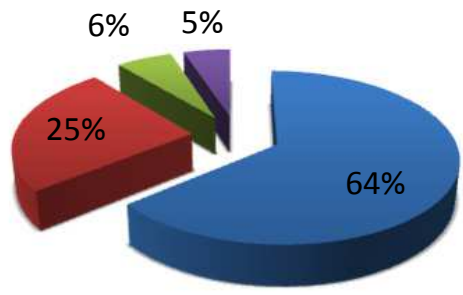

No reaction on partners' new ideas

Communication only in case of serious troubles

Fig. 6. Way of communication with partners

\begin{tabular}{|l||c|c|c|}
\hline $\begin{array}{l}\text { innovation activities evaluation / markets } \\
\text { forecasts }\end{array}$ & No & Yes & $\mathbf{n}_{\mathbf{i}}$ \\
\hline \hline No & 26 & 8 & 34 \\
\hline Yes & 37 & 68 & 105 \\
\hline $\mathbf{n}_{\mathbf{j}}$ & 63 & 76 & 139 \\
\hline
\end{tabular}

Table 7. Relations research of innovation activities evaluation and markets forecasts

Independency statistic test of two qualitative characters will be carried out for statistic dependency verification. Null fragmental hypothesis $\mathrm{DH}_{0}$ is going to be tested that random values are not depended in comparison with alternative fragmental hypothesis $\mathrm{DH}_{1}$.

$\mathrm{DH}_{0}$ : Expression of innovation effects and modeling future markets are not relate to each other.

$\mathrm{DH}_{1}$ : Expression of innovation effects and modeling future markets are related to each other.

Calculated test criterion $\chi^{2}=6,959$ for selected significance level $a=0,05$ is determined a quantile $\chi_{0,95}^{2}(1)$ of Pearson distribution $\chi_{0,95}^{2}(1)=3,841$. Because the value of test criterion was realized in critical field $(6,959>3,841)$, fragmental null hypothesis $\mathrm{DH}_{0}$ is refused on five percentage level signification and alternative fragmental hypothesis $\mathrm{DH}_{1}$ is accepted. Random values are dependent and relationship between direct expression of innovation activities effects and market progress forecasts by marketing information system was demonstrated.

Based on primary research results and statistic independency test it is possible to consider the research hypothesis as confirmed.

\section{Discussions}

In SMR, those most engaged in innovations are micro companies $(43 \%)$ and small companies (33\%) that have a Czech owner $(82 \%)$; of those, $39 \%$ operate on the domestic market within the whole Czech Republic and $27 \%$ operate only on the regional market. 
During the last three years, the majority of innovations executed by companies were organization and marketing innovations; however, companies perceive product and process innovations as more important. It generally applies that almost every product innovation should invoke at least one process innovation. When, for example, a company begins to produce a new product, a need for necessary technology that is needed for production of a new product can arise. Such a need can be fulfilled by purchase of new machinery. This is innovation of a production process. In other cases, companies maybe do not even perceive changes executed in relation to product innovations as process innovations. When a company, e.g. as a result of a new product supply, modifies activities of its sales department, in reality it is a process innovation invoked by the initial product innovation. In some cases, even product innovation of a lower intensity invokes subsequent process innovation of a higher intensity. (Theodor, 2008) singles out the beginning of the Ford car factory, as an example. Even though its first mass-produced car, the Model T, meant an important product innovation, production organization through standardization, flow production, and Taylor principles of scientific management brought a lot of much more fundamental innovations. The Model $\mathrm{T}$ was designed in such a way that it prompted a need to completely innovate the process of its production. Without such process innovations, Henry Ford would not be able to achieve his plans for production of a standardized cheap car in large series.

The result of a significant innovation activity is logical because, in general, if organizations are not prepared to continually renew their products and processes, their chances of survival are significantly jeopardized.

The main motives leading to commencement of such innovation activities are especially factors of growth of revenues and, therefore, operation profits, reaction to demand, increased quality of products or services, and increased market share. The aforementioned motives are derived from innovation needs prompted by a customer, and they serve as a starting point for creation of innovation strategy.

The structure and intensity of competition and its more or less aggressive behaviour affects competition and innovation pressure. According to (Trommsdorff \& Steinhoff, 2006), when identifying competitors, it is necessary to include, in addition to publicly acting competitors, also the potential ones, i.e. those who are not in the market yet or who do not engage in public tenders of the field in question, but have potential and strategy available. The majority of enquired companies $(87 \%)$ monitor and know the competitors' strategy and, at the same time, $93 \%$ of respondents are therefore aware of their competitive advantage.

The process of formulating strategy results in production of an innovation plan that serves as the base for creation of other partial plans. Almost all inquired companies emphasize processing of short-term plans and plans for 1 year.

The conclusion derived from the aforementioned facts is that if a company wants to receive impulses for its further development and maintain its position on the top, it is necessary to always focus on a customer who should be perceived as a driving force for progress. Highquality relations have to be built between companies and their customers. Primary research results showed that an innovation impulse primarily arises from a customer. 
Individual innovation impulses are then target-collected by a company. During the collection, in-house networks are utilized, as well as networks of external co-workers; for example, authorized dealers, etc. In practice, collection that is rather informal is more often proven good; for example, via discussions with service technicians during assemblies. A customer does not feel so bound and is willing to handle matters that he would not even mention otherwise. With regards to their own potential, companies try to convert received impulses to innovation ideas that can be utilized during the following work. The main source of innovation ideas are then employees or management of companies. With regard to the fact that companies engage their employees in seeking innovation ideas, they are also trying to motivate them.

In personal interviews, managers of some companies admitted that they do not pay enough attention to transfer of marketing information, despite the existence of some information system. At the same time, marketing management within the innovation process is usually left out, especially in the case of small and medium-sized companies. Therefore, a company management loses its insight into environment and new trends, which can cause problems with distribution, downturn of revenues, decreased profit, and it can even lead to existential problems in the future.

These days, everybody is probably aware of the importance of high-quality and timely information for correct decision making. It is also considered a matter of fact that a company has to reflect the wishes of its customers and very closely monitor development on markets, otherwise it would not be able to react accordingly and maintain its position on markets. Therefore, companies should have marketing information systems (hereinafter the "MIS") implemented. Their necessity was ultimately highlighted by results of the primary research as well. In smaller companies, such system can even have a completely informal process when all the interested parties meet and discuss a problem. It is apparent that from a certain size of a company, such "system" is completely unsuitable, and a marketing information system has to be formalized and systemically built.

Unfortunately, as shown by the primary research, the majority of companies lack a sophisticated marketing information system, modeling and analysis of the future market, analyses of customers, their behavior and unsaid needs, definition of price strategies, and analysis of new expansion areas.

Information necessary for effective functioning of a marketing information system that is necessary for acquiring innovation impulses from the market and management of the whole innovation process with the objective of increases competitiveness of a company as a whole can originate from different sources. Information received from contacts between companies' employees and customers, competitors, and suppliers within business meetings, exhibitions and trade fairs, professional seminars, execution of maintenance and repairs, etc. are considered very important.

In the ideal situation, MIS serves the purpose of:

- Collection and transfer of information - thanks to computers and other communication means, collection and transfer of information is significantly faster and, also, costs of data collection decreased. 
- Information processing - when data is saved, it has to be processed, which can sometimes be difficult without utilization of an information system, especially in a large volume of various data.

- Data interpretation and modeling - information is useful only if it has a value for a user. Collected information has to be put into context and interpreted.

- Information utilization - thanks to an information system that integrates data processing techniques with data modeling and with analytical tools supporting strategic decisions, it is possible to utilize acquired information for marketing decision making on various levels.

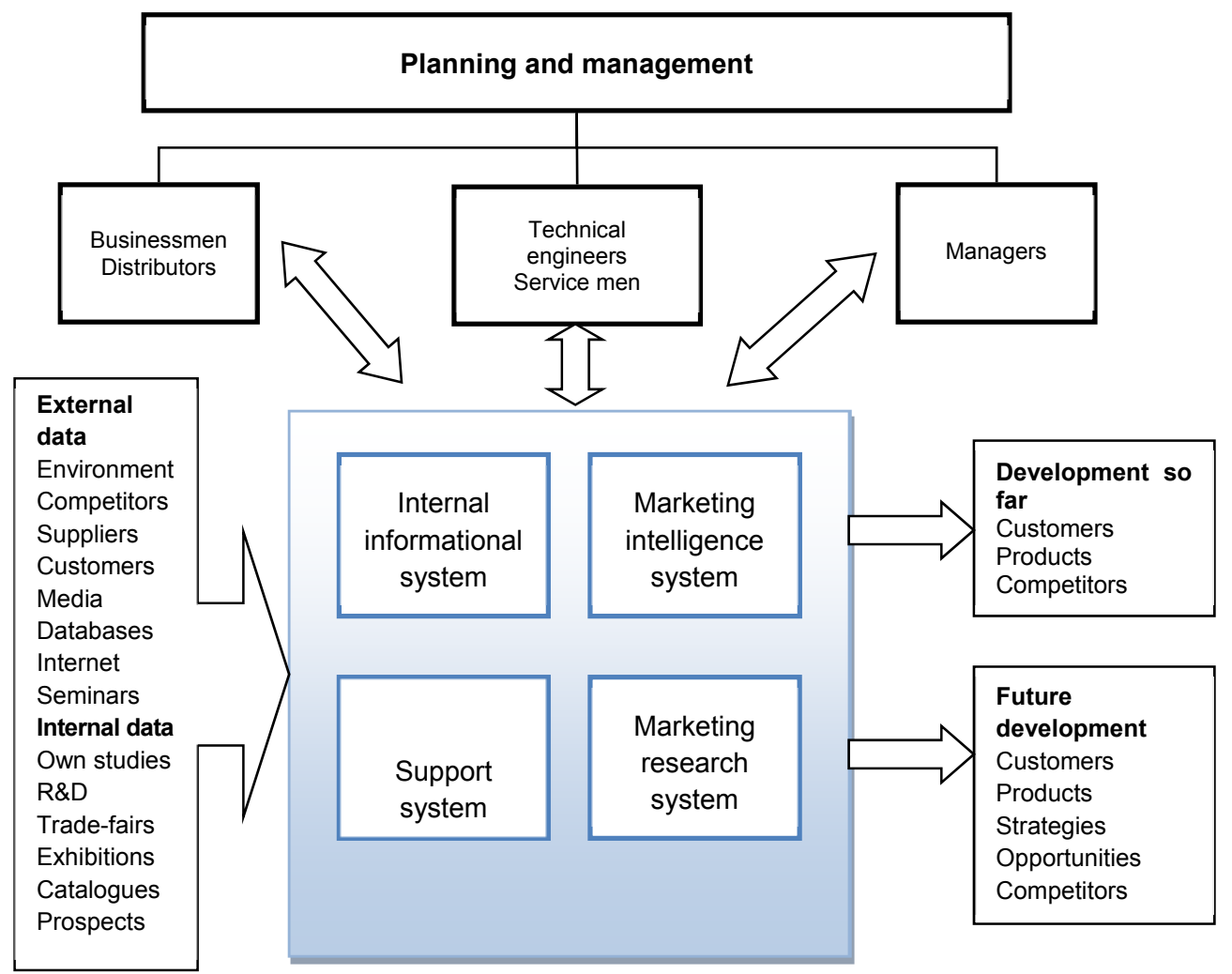

Fig. 7. Scheme of MIS

The majority of renowned companies thoroughly monitor all their employees' contacts and information received about them. Such information is very important and, in principle, it is a company's asset because staff handles all dealing at its costs. It is a problem of effect of a company's culture and due verification of evaluation and a bonus system to make sure that staff members accept organization rules and enter information into MIS via standard forms. Especially for small and medium-sized companies, such a system is irreplaceable, but its accessibility is not easy. That is, employees consider acquired information their personal know-how and intend to utilize it for strengthening of their own positions only. However, 
we know from experience of foreign companies that enforcement of a company's interests is possible, but it requires long-term influence on a company's culture and, sometimes, slight "breach" of human rights of employees (Solar, 2006).

Limited funds of small and medium-sized companies significantly limit possibilities of utilization of external information sources for MIS whose level keeps increasing, but prices of the services are high. Therefore, it is necessary to carefully consider every utilization of their services. Organizational provision of collection of free external data from the Internet and other external sources is also problematic for small and medium-sized companies. However, it applies to them as well, that even small and medium-sized companies have to collect, save, and utilize information so that they can improve their decision making, communication with customers, suppliers, and consumers so that they are able to maintain their competitive advantage.

Solution of marketing and MIS problems that are available in professional literature, e.g. (Ranchhod \& Gurau, 2007), are very complex and systemic, but practically useless for small, as well as a lot of medium-sized companies. If we examine their organization structure, we will find out that marketing is often provided by one staff member who is organizationally placed either in the sales department, or the department of the company's CEO. There is the same staffing for controlling of small companies whose performance is again provided (in the optimistic variant) by one staff member usually placed in the financial department where such person is usually also assigned a lot of other functions.

The authors of the article see a possible solution in nomination of a team consisting of more professions that will ensure motivation and evaluation of results of collection of external and internal information for MIS by all the company's employees, solution of problems related to authorization of access to the information stored in MIS, evaluation of information from MIS from the aspect of comparison of the company's performance with its main competitors, and proposing measures within strategy updating. Such team should be led by a CFO, and it should consist of professions necessary for evaluation of products, technologies, customers, suppliers, and markets, i.e. representatives of all main functions in a company. Selection of particular team members would be carried out by a company CEO, in cooperation with a team leader. MIS would represent the technical provision of work of the team, and a designated worker also carrying out collection of internal and external information would be responsible for its operation.

The proposed access would simplify realization of a necessary change of a style of work with information, regular saving of critical data to the system, and enable its sharing by other staff members. It is a complicated problem in the area of a company culture, and the proposed system of team management could contribute to its solution. It is necessary to realize that to acquire information is one thing, but to process it, interpret it, and subsequently use it is an entirely different thing. Therefore, it is necessary to think about an information system, create certain rules, procedures, and processes so that everybody in a company would know what to do.

A complex marketing information system has a wide range of use in a company. It is able to inform on the current market development and performance of its own company, as well as competitors. The basic information structure of MIS is as follows: 
- Information on market subjects (suppliers, customers, competitors).

- Information on market objects (products and services purchased, as well as produced).

- Information on business cases (data transfer from customers' and suppliers' invoices).

- Information on contacts (evaluation of contacts, planning of contacts).

- Information on demands (filling, performance evaluation).

In addition to the basic structure, MIS can also contain software tools for execution of analyses (SWOT, Pareto, Portfolio, etc.), management of projects, administrative activities, and various supporting tasks. By utilizing information from MIS, it is possible to decrease risks of strategic decisions, prepare to a high standard for dealing with partners, increase purchase effectiveness, or improve the marketing mix for a certain product.

Necessary condition for developments in marketing and innovation activities is working MIS. MIS should be an indivisible part of the Executive Information System (hereinafter the "EIS"). Currently there are many Enterprise Resource Planning (hereinafter the "ERP") systems to choose from. These ERP systems can be enhanced when connected to Supply Chain Management (hereinafter the "SCM") and Customer Relationship Management (hereinafter the "CRM") systems. In the Czech Republic the EISs which support decision making are not used very frequently. An array of large Czech companies therefore implements the MIS as a way to improve their existing ERP system. Some ERP systems partially serve as SCM and CRM with obvious limitations. The philosophy of integration of the MIS into the existing IS is demonstrated in Figure 8.

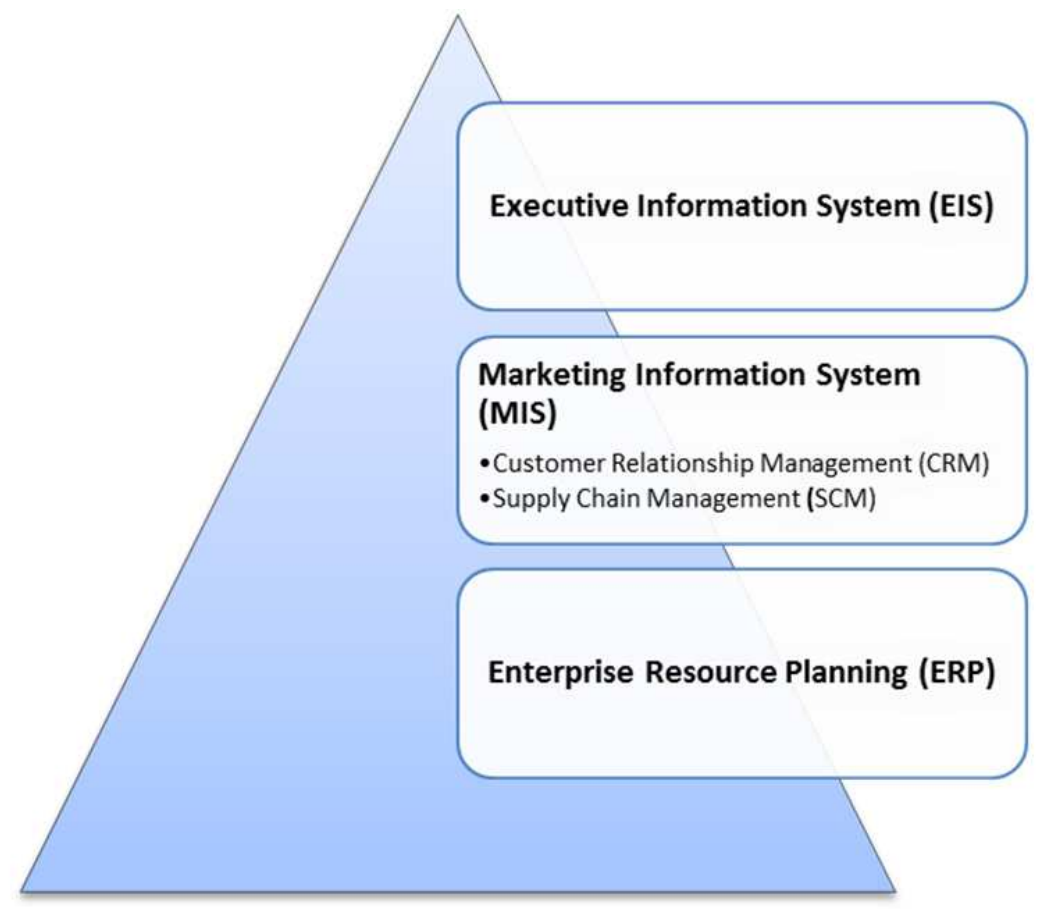

Fig. 8. Scheme of the integration of the MIS into the existing IS structure 
MIS implementation itself, from preparation, over installation, to verification lasts several months; however, significant contributions for management can be expected only after databases are filled, i.e. within 1 to 2 years. The authors also perceive utilization of the newest versions of MIS in small companies as problematic. Here, upon agreement with a supplier, it will be necessary to accede to implementation of simplified versions because the newest versions - very extensive ones - could not be filled and it would not even make sense to fill them because of significantly simplified process, as well as the organization structure of small companies. These requirements are logical, and the system supplier should be able to flexibly react to them. The ability of a supplier to ensure interconnection between MIS and the existing basic ERP system is also a limiting factor.

\section{Conclusion}

The article summarizes the issue of management of innovation activities and findings of empirical research. It strives to show the importance of information provision of innovation activities linked to the overall effectiveness and competitiveness of an entrepreneurship. As the research proved, information support for modeling of future markets, analyses of customers, their behavior, and needs is extremely important in innovation marketing and, therefore, innovation activities should be supported by a successfully implemented and functioning marketing information system. Only then, is it possible to recognize and process potential innovation signals, acquire necessary information, and carry out decisions as for which innovations a company would focus and spend resources on.

Several hypotheses were declared before the research was commenced. In the area of potential predetermining more or less innovative companies, a company's size used to be considered the key factor when innovation activities are usually undertaken by large and medium-sized companies that have sufficient resources for it. However, this hypothesis was not confirmed because in the South Moravian Region, the majority of innovations are undertaken by micro companies and small companies (these groups form a total of $75 \%$ respondents).

In the marketing area, it was assumed that direct expression of effects of innovation activities strongly depends on market development prognoses, and marketing information systems have to help with their predictions. Based on the found facts and statistic independency test, it is possible to declare this hypothesis confirmed.

\section{Acknowledgement}

The author would like to thank participants at the research survey and Faculty of Business and Management BUT for its support within research projects and this publication.

\section{References}

Ahuja, G. \& Katila, R. (2001). Technological acquisition and the innovative performance of acquiring firms: a longitudinal study. Strategic Management Journal, Vol. 22, No. 3, 197-220, ISSN 1097-0266

Allak, B. (2010). Evaluating the Adoption and use Internet-based Marketing Information system to Improve Marketing Intelligence (The Case of Tourism SMEs in Jordan). International Journal of Marketing Studies, Vol. 2, No. 2, 87-101, ISSN 1918-719X

Dinis, A. (2004). Marketing and Innovation: Useful tools for competitiveness in rural and Peripheral Area. European Planning Studies, Vol. 14, No. 1, 9-22, ISSN 0965- 4313 
Doloreux, D. (2004). Regional Networks of Small and Medium Sized Enterprises: Evidence from the Metropolitan Area of Ottawa in Canada. European Planning Studies, Vol. 12, No. 2, 173-189, ISSN 0965-4313

Ernst, H. (2001). Patent applications and subsequent changes of performance: evidence from time-series cross-section analyses on the firm level. Research Policy, Vol 30, No. 1, 143-157, ISSN 0048-7333

Hamel, G. \& Green, B. (2007). The Future of Management. Harvard Business School Press, ISBN 978-1-4221-0250-3, Boston, USA

Hauser, J.; Tellis, J. G. \& Griffin, A. (2006). Research on Innovation: A Reviwe and Agenda for Marketing Science. Marketing Science, Vol. 25, No. 6, 687-717, ISSN 0732- 2399

Chatyipanagiotou, K.; Vassilikopoulou, A. \& Siomkos, G. (2008). An Empirical investigation of the relationship between market orientation and MrkIS effectiveness in upscale hotels in Greece. Journal of Targeting, Measurement and Analysis for Marketing, Vol. 16, No. 4, 285-297, ISSN 0967- 3237

Kislingerova, E. (2008). Inovace nastroju ekonomiky a managementu organizaci, C.H.Beck, ISBN 978-80-7179-882-8, Prague, Czech Republic

Kosturiak, J. \& Chal, J. (2008). Inovace: Vase konkurencni vyhoda, Computer press, ISBN 97880-251-1929-7, Brno, Czech Republic

Maciariello, J. (2009). Marketing and Innovation it he Drucker Management system. Journal of the Academy of Marketing Science, Vol. 37, No. 1, 35-49, ISSN 0092- 0703

OECD (2005). Oslo Manual: Guidelines for Collecting and Interpreting Innovation Data, OECD Publishing, ISBN 92-64-01308-3, Paris, France

Ranchhod, A. \& Gurau, C. (2007). Marketing Strategies a Contemporary Approach, Pearson Education Limited, ISBN 978-0-273-70674-8, Essex, U.K.

Reid, R. \& Bojanic, D. (2009). Hospitality Marketing Management, Wiley, ISBN 978-0-47008858-6, New Jersey, USA

Schumpeter, J. (1912). Theorie der wirtschaftlichen Entwicklung, Duncker und Humblot, Leipzig, Germany

Skarzynski, P. \& Gibson, R. (2008). Innovation to the Core: A Blueprint for Transforming the Way Your Company Innovates, Harvard Business School Press, ISBN 978-1-4221-0251-0, Boston, USA

Solar, J. (2006). The Problems of Efficient Functioning Appraising the Efficiency and Benchmarking in the Production Companies, Proceedings of Management, Economics and Business Development in the New European Conditions, ISBN 80-7204-454-0, Brno, May 2006

Stuart, T. (2000). Interorganizational alliances and the performance of firms: a study of growth and innovation rates in a high-technology industry. Strategic Management Journal, Vol. 21, No. 8, 791-811, ISSN 1097-0266

Synek, M. (2011). Manazerska ekonomika, Grada Publishing, ISBN 978-80-247-3494-1, Prague, Czech Republic

Theodor, M. (2008). Intensity of innovations and impulses of innovations. Ekonomika a management, Vol. 2, No. 3.8 pp., ISSN 1802-8934

Tidd, J. \& Bessant, J. (2009). Managing Innovation: Integrating Technological, Market and Organizational Change, Wiley, ISBN 978-0-4709-9810-6, West Sussex, U.K.

Trommsdorff, V. \& Steinhoff, F. (2006). Innovationsmarketing, Vahlen, ISBN 978-3-8006-20227, Germany

Valenta, F. (2001). Inovace v manazerske praxi, Velryba, ISBN 80-85860-11-2, Prague, Czech Republic

Zizlavsky, O. (2009). Approaches to Innovation Performance Increasing in Manufacturing Companies, Brno University of Technology, ISBN 978-80-214-4091-3, Brno, Czech Republic 


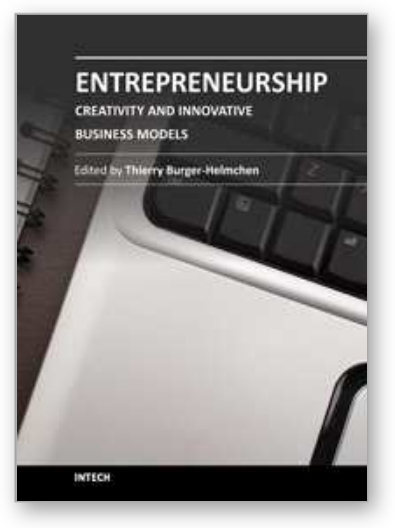

\author{
Entrepreneurship - Creativity and Innovative Business Models \\ Edited by Prof. Thierry Burger-Helmchen
}

ISBN 978-953-51-0069-0

Hard cover, 190 pages

Publisher InTech

Published online 29, February, 2012

Published in print edition February, 2012

What are the differences between an entrepreneur and a manager? According to Schumpeter, the main difference lies in the entrepreneur's ideas, creativity, and vision of the world. These differences enable him to create new combinations, to change existing business models, and to innovate. Those innovations can take several forms: products, processes, and organizations to name a few. In this book, an array of international researchers take a look at the visions and actions of innovative entrepreneurs to be at the source of new ideas and to foster new relationships between different actors to change the existing business models.

\title{
How to reference
}

In order to correctly reference this scholarly work, feel free to copy and paste the following:

Ondrej Zizlavsky (2012). The Development and Implementation of Marketing Information System Within Innovation: The Increasing of Innovative Performance, Entrepreneurship - Creativity and Innovative Business Models, Prof. Thierry Burger-Helmchen (Ed.), ISBN: 978-953-51-0069-0, InTech, Available from: http://www.intechopen.com/books/entrepreneurship-creativity-and-innovative-business-models/thedevelopment-and-implementation-of-marketing-information-system-within-innovation-the-increasing-

\section{INTECH}

open science | open minds

\section{InTech Europe}

University Campus STeP Ri Slavka Krautzeka 83/A 51000 Rijeka, Croatia Phone: +385 (51) 770447 Fax: +385 (51) 686166 www.intechopen.com

\section{InTech China}

Unit 405, Office Block, Hotel Equatorial Shanghai No.65, Yan An Road (West), Shanghai, 200040, China 中国上海市延安西路65号上海国际贵都大饭店办公楼405单元 Phone: +86-21-62489820

Fax: +86-21-62489821 
(C) 2012 The Author(s). Licensee IntechOpen. This is an open access article distributed under the terms of the Creative Commons Attribution 3.0 License, which permits unrestricted use, distribution, and reproduction in any medium, provided the original work is properly cited. 